\title{
Reconstruction of cumulative fission yield curve and geochemical behaviors of fissiogenic nuclides in the Oklo natural reactors
}

\author{
Hiroshi Hidaka*, TAKashi Konishi and AKimasa Masuda \\ Department of Chemistry, The University of Tokyo, Tokyo 113, Japan
}

(Received November 25, 1991; Accepted July 20, 1992)

\begin{abstract}
Isotopic ratios and elemental abundances of rare earth elements (REE), $\mathrm{Rb}, \mathrm{Sr}, \mathrm{Zr}, \mathrm{Mo}, \mathrm{Ru}, \mathrm{Pd}$, $\mathrm{Ag}, \mathrm{Te}, \mathrm{Ba}$ and $\mathrm{U}$ in four samples from two Oklo Reactor Zones 7, 8, 9 and 10 were determined by thermal ionization mass spectrometry. These elements have unusual but reasonable isotopic anomalies due to the effect of fission and/or neutron capture reactions. In order to discuss the retentivity of fissiogenic nuclides, the fission product yield curves covering the wide mass range from 90 to 160 were reconstructed on the basis of our results. We have estimated the behavior of fissiogenic nuclides by means of the differences between the measured curves and empirical ones.

From comparison of these two sets of curves, measured and empirical, the behaviors of fissiogenic nuclides were deduced. Our results are in agreement with previous Oklo work at the following points:

(I) $\mathrm{Ru}, \mathrm{Pd}, \mathrm{Te}$ and most of a series of REE (except for $\mathrm{La}$ and/or $\mathrm{Ce}$ ) have been well retained in the samples,

(II) $\mathrm{Rb}, \mathrm{Sr}$ and $\mathrm{Ba}$ have been lost to a great extent, and their isotopic ratios are nearly the same as those of terrestrial standard values, and

(III) $\mathrm{Zr}$, Mo and $\mathrm{Ag}$ have been partially removed from the reactors. The behaviors of $\mathrm{Zr}$ and Mo seem to have been highly affected by the chemical and geological environments in and around the reactors.

The present work reveals that, among REE, La and Ce might have been partially removed in contrast to the good retention of other REE. Also, there is a possible remobilization of ${ }^{90} \mathrm{Sr}$ during operation of the Oklo reactors.
\end{abstract}

\section{INTRODUCTION}

Burial in suitable rock strata is the current concept for radioactive waste disposal. In this connection, the detailed understanding of the behaviors of radioactive nuclides in the geological media is required. Geochemical studies on the Oklo natural reactors are well known as natural analogues of radioactive waste repository, and are expected to provide us with useful information on the mobilities of various fissiogenic nuclides. Many of fissiogenic nuclides produced in these reactors have been preserved for about 2.0 Ga. Except for the Oklo reactors, it is impossible to trace the geochemical behavior of radioactive nuclides for a long time interval.

From the view point of stability of elements between solid and liquid phases, the mobilities of various elements have been predicted by use of Eh-pH diagrams (Brookins, 1978, 1984). In general, most of these data are in agreement with the observations at the Oklo site. Many studies on the isotopic compositions of various elements in Oklo samples have been performed, and the behaviors of fissiogenic nuclides have been discussed (The Oklo Phenomenon, 1975; Roth, 1977; The Natural Fission Reactors, 1978; De Laeter et al., 1980; Holliger and Devillers, 1981;

${ }^{*}$ Present Address: Department of Chemistry, Tokyo Metropolitan University, Tokyo 192-03, Japan 
Loss et al., 1984; Curtis et al., 1989). These works as a whole cover nearly all aspects of isotopic abundances, but in general have been rather fragmentary individually, although they had focal points of their own in order to understand the features of the Oklo reactors.

We have evaluated the mobilities of fissiogenic nuclides on the basis of cumulative fission product yield curves, and have recognized that the deviation of measured curves from empirical ones can be one of the useful indicators of the mobilities of fissiogenic nuclides. In our attempt to reconstruct the fission product yield curves, attention was paid to rare earth elements (REE), Rb, Sr, Zr, Mo, Ru, Pd, Ag, Cd, Sn, Te, $\mathrm{Ba}$ and so on. Here we report the isotopic ratios and abundances of REE, $\mathrm{Rb}, \mathrm{Sr}, \mathrm{Zr}, \mathrm{Mo}, \mathrm{Ru}$, $\mathrm{Pd}, \mathrm{Ag}, \mathrm{Te}$ and $\mathrm{Ba}$ in samples from Oklo ores by the use of thermal ionization mass spectrometry.

\section{SAMPLES}

Since the discovery of the first Oklo reactor in 1972, sixteen reactors have been found. Geological study on the Oklo uranium ore deposit has been reported by Gauthier-Lafaye and Weber (1989).
In our present study, four samples were analyzed. The official nomenclatures of these four samples are unknown. One is "sample A" of our previous REE study (Hidaka et al., 1988). This sample comes from reactor Zone 7, 8, 9 and it is uraninite. The other three samples from Zone 10 were collected from a borehole. Zone 10 has been located underground, and is now being investigated in detail (Holliger, 1991). A schematic cross section of Zone 10 is shown in Fig. 1. SF-29 is a blackshale, and contains uraninite. SF-42 is composed of two parts, slate (SF-42SL) and sandstone (SF-42SS), and is located around the boundary between sandstone and the center of reactor (Bunno et al., 1985). Descriptions of samples are compiled in Table 1. Three samples from Zone 10 are not high-grade $\mathrm{U}$ ores, but it is easily recognized that ${ }^{235} \mathrm{U}$ is depleted and the fission products are contained to some extent in each sample. The neutron fluence evaluated from Gd isotopes is also listed in Table 1.

\section{Chemical Procedures}

Rock samples were digested by hot HF, $\mathrm{HClO}_{4}$ and $\mathrm{HNO}_{3}$, and were finally dissolved in

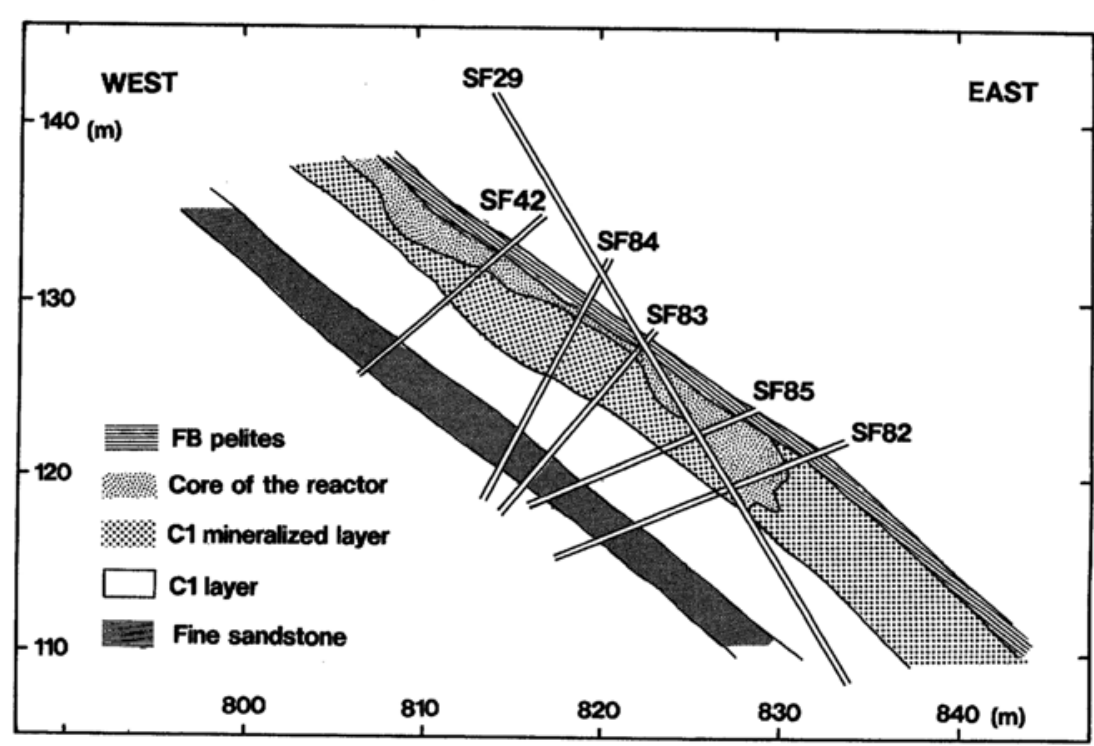

Fig. 1. Geologic cross section of reactor zone 10 (Holliger, 1991). Each name of stratigraphic sections has been defined by Gauthier-Lafaye and Weber (1989). 
Table 1. Description of samples

\begin{tabular}{|c|c|c|c|c|}
\hline & A & SF-29 & SF-42SL & SF-42SS \\
\hline $\begin{array}{l}\text { Zone } \\
\text { Rock Type }\end{array}$ & $\begin{array}{l}7,8,9 \\
\text { uraninite }\end{array}$ & $\begin{array}{l}10 \\
\text { blackshale }\end{array}$ & $\begin{array}{l}10 \\
\text { slate }\end{array}$ & $\begin{array}{l}10 \\
\text { sandstone }\end{array}$ \\
\hline U conc. (wt. \%) & 51.1 & 5.86 & 0.256 & 0.0427 \\
\hline $\begin{array}{l}{ }^{238} U /{ }^{235} U^{\text {a) }} \\
\text { neutron }\end{array}$ & $146.8 \pm 0.3$ & $158.7 \pm 0.7$ & $151.7 \pm 1.6$ & $151.7 \pm 2.1$ \\
\hline $\begin{array}{l}\text { fluence } \\
\left(\times 10^{20} \mathrm{n} / \mathrm{cm}^{2}\right)\end{array}$ & 1.9 & 0.28 & 0.17 & 0.085 \\
\hline
\end{tabular}

a) Errors are $2 \sigma$ mean. Terrestrial standard value of ${ }^{238} U /{ }^{235} U$ is $137.5 \pm 0.2$

b) The values are calculated from $\mathrm{Gd}$ isotope ratios (Hidaka and Masuda, 1988).

diluted $\mathrm{HCl}$. Fractions for each element of REE were separated by cation exchange resin columns with $\alpha$-hydroxyisobutyric acid ( $\alpha$-HIBA) (Hidaka et al., 1988). Separation procedures and mass spectrometric techniques of other elements were conventional: $\mathrm{Rb}$ and $\mathrm{Sr}$ (Faure and Powell, 1972), Zr (Shima, 1978), Mo (Tromp et al., 1981, Kawashima, 1990), Ru (Terada et al., 1975), Pd, Ag and Te (Loss et al., 1983), $\mathrm{Ba}$ (Eugster et al., 1969), U (Chen and Wasserburg, 1981). In mass spectrometry of $\mathrm{Ru}, \mathrm{Pd}, \mathrm{Ag}$ and $\mathrm{Te}$, a V-shaped Re single filament with silica gel and phosphoric acid was employed. Since there are some contaminant peaks attributed to silica gel and phosphoric acid, careful preheating of a filament at about $1000^{\circ} \mathrm{C}$ was necessary prior to beginning of the measurements.

At first, isotopic measurements were performed by thermal ionization mass spectrometer (JEOL-JMS-05RB) equipped with an electron multiplier. In the isotopic measurements, the absence of isobaric interferences was always confirmed by monitoring non isobaric mass range. And in prebaking of filaments, much attention was paid to reduce the natural Mo contamination from the Re filament. In the measurement of Pd, some contamination at mass number 110 could not be completely removed. The origin of this contamination was not definitely identified. Thus, the abundance of ${ }^{110} \mathrm{Pd}$ could not be precisely determined.

After the determination of isotopic compositions, elemental abundances were measured by isotope dilution method. Moreover, the determinations of monoisotopic abundances of REE (Pr, Tb, Ho and Tm) were carried out by ICPMS (VG PlasmaQuad type I)(Hirata et al., 1988).

\section{Results AND Discussion}

Cumulative fission product yield curves for ${ }^{235} U$, ${ }^{238} \mathrm{U}$ and ${ }^{239} \mathrm{Pu}$

Isotopic compositions and concentrations of various elements (REE, $\mathrm{Rb}, \mathrm{Sr}, \mathrm{Zr}, \mathrm{Mo}, \mathrm{Ru}, \mathrm{Pd}$, $\mathrm{Ag}, \mathrm{Te}$ and $\mathrm{Ba}$ ) in four samples are presented in Tables 2 and 3. On the basis of these data, the proportions of fissiogenic nuclides to total abundances of nuclides could be approximately evaluated. Details of this evaluation were reported previously (Hidaka et al., 1988). These evaluated values are compiled in Table 4.

In this paper, "relative fission yield" refers to the relative number of atoms of fissiogenic nuclide. In practice, abundance (ppm) of each of fissiogenic nuclides is divided by its mass and the obtained value is designated as ppm/mass. Therefore, plotting $\mathrm{ppm} / \mathrm{mass}$ values against mass number corresponds to relative fission product yield curve (Hidaka et al., 1988). The comparison of these curves and the reference curves makes it possible to estimate the retentivity of fissiogenic nuclide in Oklo samples (Hagemann and Roth, 1978). As to SF-42SS, the amounts of fissiogenic nuclides are much less than those in other three samples (see Table 4). It is actually impossible to construct a fission product yield curve for SF-42SS because of small amount of fission products in the sample, and it is difficult to discuss the behavior of nuclides in SF-42SS by use of fission product yield curves. Therefore the discussions will be restricted to the remaining three samples, A, SF-29 and SF-42SL.

It is empirically well known that fission product yield curves for uranium 235, 238 and plutonium 239 have binary maximal peaks around regions of $90-100$ and $130-140$ in mass number. The patterns of fission product yields are slightly different among these three nuclides. In the Oklo natural reactors, uranium 235, 238 and plutonium 239 have fissioned. Using conven- 
Table 2. Isotopic compositions (atom \%)

(a) REE

\begin{tabular}{|c|c|c|c|c|c|c|}
\hline & & Standard & $\mathrm{A}^{*}$ & SF-29 & SF-42SL & SF42-SS \\
\hline \multirow[t]{2}{*}{$\mathrm{La}$} & 138 & 0.0888 & 0.0618 & 0.0253 (2) & $0.0552(5)$ & 0.0809 \\
\hline & 139 & 99.911 (209) & 99.938 & $99.975(505)$ & $99.945(873)$ & 99.919 (305) \\
\hline \multirow[t]{4}{*}{$\mathrm{Ce}$} & 136 & 0.192 (4) & 0.114 & 0.0826 & 0.169 (5) & 0.172 (1) \\
\hline & 138 & 0.241 (3) & 0.159 & 0.111 (1) & $0.222(5)$ & 0.231 (1) \\
\hline & 140 & $88.30(10)$ & 73.64 & 69.39 (11) & 84.39 (24) & $86.26(2)$ \\
\hline & 142 & $11.26(10)$ & 26.08 & $30.42(9)$ & 15.22 (4) & 13.34 (2) \\
\hline \multirow[t]{7}{*}{$\mathrm{Nd}$} & 142 & 27.19 (6) & $4.97(2)$ & 8.05 & $20.47(3)$ & 23.85 (4) \\
\hline & 143 & 12.18 & 24.44 (3) & $22.58(7)$ & 15.56 (2) & 14.00 (2) \\
\hline & 144 & $23.80(4)$ & $27.18(6)$ & $26.88(7)$ & 24.75 (5) & 24.41 (4) \\
\hline & 145 & 8.29 (2) & $16.81(3)$ & 15.59 (5) & 10.70 (2) & 9.64 (2) \\
\hline & 146 & $17.17(3)$ & 15.13 (1) & $15.39(5)$ & 16.49 (2) & 16.79 \\
\hline & 148 & $5.74(1)$ & $7.74(1)$ & 7.55 (2) & 6.51 (2) & 6.06 (1) \\
\hline & 150 & 5.62 (1) & 3.73 & 3.97 (1) & $5.52(2)$ & $5.26(1)$ \\
\hline \multirow[t]{7}{*}{ Sm } & 144 & 3.12 (1) & $0.343(9)$ & $1.202(2)$ & 2.57 (2) & 2.95 (1) \\
\hline & 147 & 15.11 & 52.76 (1) & $40.62(6)$ & 22.20 (14) & 17.90 \\
\hline & 148 & $11.30(2)$ & 2.54 & 5.39 (1) & $9.68(4)$ & $10.73(2)$ \\
\hline & 149 & 13.86 & 1.04 & 1.54 & $5.90(5)$ & $9.53(2)$ \\
\hline & 150 & 7.39 (1) & 25.88 & 23.34 (3) & $16.36(10)$ & 12.07 (2) \\
\hline & 152 & 26.65 & 12.96 (1) & 17.74 (2) & 24.15 (14) & 25.66 (5) \\
\hline & 154 & 22.57 (3) & 4.48 (1) & 10.17 (1) & $19.13(12)$ & 21.17 (4) \\
\hline \multirow{2}{*}{$\mathrm{Eu}$} & 151 & $47.88(6)$ & 38.50 & 37.41 (5) & $42.66(12)$ & \\
\hline & 153 & $52.12(7)$ & 61.50 & $62.59(8)$ & $57.34(16)$ & \\
\hline \multirow[t]{7}{*}{ Gd } & 152 & 0.201 (2) & $13.73(3)$ & 4.83 (1) & $1.201(2)$ & 0.517 \\
\hline & 154 & 2.17 (2) & $4.38(1)$ & 3.09 (1) & 2.450 (4) & 2.274 (2) \\
\hline & 155 & $14.78(3)$ & 0.844 (1) & 4.49 (1) & 8.54 (2) & 12.49 (2) \\
\hline & 156 & $20.46(6)$ & 32.69 (4) & $29.95(5)$ & $26.77(7)$ & $22.80(5)$ \\
\hline & 157 & $15.67(6)$ & 0.146 & 0.745 (2) & 4.37 (1) & 9.18 (2) \\
\hline & 158 & 24.79 (9) & $31.92(4)$ & $36.81(6)$ & $35.26(9)$ & $31.06(6)$ \\
\hline & 160 & $21.92(6)$ & 16.29 (2) & 20.08 (3) & 21.39 (4) & 21.68 (4) \\
\hline \multirow[t]{7}{*}{ Dy } & 156 & 0.060 & $0.0706(15)$ & - & - & - \\
\hline & 158 & 0.968 (6) & 0.117 (2) & - & - & 0.123 \\
\hline & 160 & 2.41 (1) & 3.03 & $2.74(2)$ & 2.30 & 2.410 (3) \\
\hline & 161 & 19.05 (4) & 18.60 & 19.01 (4) & $19.30(5)$ & 19.06 (4) \\
\hline & 162 & $25.66(4)$ & 27.93 (1) & $26.60(6)$ & $26.82(8)$ & 25.67 (5) \\
\hline & 163 & 24.71 (4) & 30.01 (1) & $26.04(6)$ & $24.91(8)$ & 25.27 (5) \\
\hline & 164 & $28.00(11)$ & 20.23 (2) & $25.62(5)$ & 26.66 (9) & 27.47 (5) \\
\hline \multirow[t]{6}{*}{ Er } & 162 & 0.1450 & 0.139 & & - & $0.151(3)$ \\
\hline & 164 & $1.602(2)$ & 1.58 & & 1.58 & $1.58(3)$ \\
\hline & 166 & 33.37 (2) & 34.91 (1) & & $33.52(9)$ & $33.61(7)$ \\
\hline & 167 & 22.87 (4) & 13.94 (1) & & 21.57 (6) & 21.51 (4) \\
\hline & 168 & 26.99 (4) & 35.18 & & $18.28(10)$ & 28.26 (5) \\
\hline & 170 & $15.00(3)$ & 14.38 (1) & & 15.04 (6) & 14.88 (3) \\
\hline \multirow[t]{7}{*}{$\mathrm{Yb}$} & 168 & $0.1364(4)$ & $0.0425(28)$ & 0.105 (1) & & - \\
\hline & 170 & $3.072(3)$ & $4.62(1)$ & 3.261 (4) & & $3.06(1)$ \\
\hline & 171 & 14.29 (2) & 13.88 & 14.30 (1) & & $14.30(5)$ \\
\hline & 172 & 21.79 (2) & 22.01 (1) & 21.93 (1) & & 21.99 \\
\hline & 173 & 16.14 & 15.55 (2) & 16.06 (1) & & 16.04 (3) \\
\hline & 174 & 31.78 (2) & 31.38 (2) & 31.70 (2) & & 31.91 (8) \\
\hline & 176 & 12.79 (2) & 12.51 (2) & 12.65 (1) & & 12.70 (7) \\
\hline \multirow[t]{2}{*}{ Lu } & 175 & 97.44 (9) & 99.40 & 98.12 (10) & $97.60(9)$ & \\
\hline & 176 & 2.56 & 0.600 & 1.88 & 2.40 & \\
\hline
\end{tabular}


(b) Others

\begin{tabular}{|c|c|c|c|c|c|c|}
\hline & & standard & A & SF-29 & SF-42SL & SF-42SS \\
\hline \multirow[t]{2}{*}{$\mathbf{R b}$} & 85 & 72.17 (19) & 72.05 (27) & & & \\
\hline & 87 & $27.83(8)$ & $27.95(11)$ & & & \\
\hline \multirow[t]{4}{*}{$\mathrm{Sr}$} & 84 & $0.558(3)$ & 0.560 & & & \\
\hline & 86 & $9.863(2)$ & $9.876(14)$ & & & \\
\hline & 87 & $7.005(1)$ & 7.115 (9) & & & \\
\hline & 88 & $82.57(2)$ & 82.45 (12) & & & \\
\hline \multirow[t]{5}{*}{$\mathrm{Zr}$} & 90 & $50.95(6)$ & 36.68 (17) & $50.16(14)$ & 50.55 (19) & $50.73(18)$ \\
\hline & 91 & $11.25(2)$ & $14.65(7)$ & $12.28(8)$ & $12.06(5)$ & $11.76(3)$ \\
\hline & 92 & $17.28(2)$ & $18.62(7)$ & $17.16(9)$ & $17.14(9)$ & $17.18(3)$ \\
\hline & 94 & $17.63(3)$ & $19.65(13)$ & $17.29(10)$ & $17.41(9)$ & $17.47(6)$ \\
\hline & 96 & $2.90(1)$ & $10.40(9)$ & 3.09 (1) & $2.83(2)$ & 2.85 (1) \\
\hline \multirow[t]{7}{*}{ Mo } & 92 & $14.63(2)$ & & $7.01(6)$ & $14.32(15)$ & \\
\hline & 94 & $9.21(1)$ & & $4.72(4)$ & $9.18(10)$ & \\
\hline & 95 & $15.93(2)$ & & $20.99(10)$ & $15.85(18)$ & \\
\hline & 96 & $16.67(2)$ & & $8.56(8)$ & $16.82(24)$ & \\
\hline & 97 & $9.54(1)$ & & $17.01(9)$ & $9.90(12)$ & \\
\hline & 98 & $24.23(5)$ & & $24.03(14)$ & $24.22(40)$ & \\
\hline & 100 & $9.79(2)$ & & $17.68(7)$ & $9.70(12)$ & \\
\hline \multirow[t]{7}{*}{$\mathrm{Ru}$} & 96 & $5.53(1)$ & - & - & & \\
\hline & 98 & $1.86(1)$ & - & - & & \\
\hline & 99 & $12.73(4)$ & $29.74(7)$ & 30.80 (9) & & \\
\hline & 100 & $12.62(3)$ & - & - & & \\
\hline & 101 & 17.03 (4) & $33.06(8)$ & 30.87 (9) & & \\
\hline & 102 & $31.49(7)$ & $24.92(6)$ & $26.61(7)$ & & \\
\hline & 104 & $18.73(5)$ & $12.59(2)$ & $11.72(5)$ & & \\
\hline \multirow[t]{6}{*}{ Pd } & 102 & $1.027(3)$ & - & - & - & \\
\hline & 104 & $11.24(3)$ & $5.64(2)$ & - & $4.22(7)$ & \\
\hline & 105 & $22.57(8)$ & $59.13(30)$ & $60.68(53)$ & $66.37(82)$ & \\
\hline & 106 & $27.24(8)$ & $26.53(13)$ & $24.88(22)$ & $21.32(52)$ & \\
\hline & 108 & $26.22(9)$ & $6.27(3)$ & $9.69(6)$ & $5.17(11)$ & \\
\hline & 110 & $11.70(6)$ & 2.44 (1) & $<4.8$ & $<3.0$ & \\
\hline \multirow[t]{2}{*}{$\mathrm{Ag}$} & 107 & $51.93(7)$ & & 60.95 (19) & 52.49 (11) & $51.58(21)$ \\
\hline & 109 & $48.07(6)$ & & $39.05(12)$ & $47.51(10)$ & $48.42(21)$ \\
\hline \multirow[t]{8}{*}{$\mathrm{Te}$} & 120 & $0.0968(4)$ & & - & - & - \\
\hline & 122 & $2.620(21)$ & & - & - & - \\
\hline & 123 & $0.915(7)$ & & - & - & - \\
\hline & 124 & 4.692 (37) & & - & - & $5.80(5)$ \\
\hline & 125 & $7.094(32)$ & & $1.37(3)$ & $3.34(5)$ & $13.20(42)$ \\
\hline & 126 & $18.78(8)$ & & $2.84(3)$ & $4.97(8)$ & $14.56(54)$ \\
\hline & 128 & $31.80(8)$ & & 16.84 (11) & 39.04 (7) & $29.71(52)$ \\
\hline & 130 & $34.00(9)$ & & 78.95 (52) & $52.65(9)$ & $36.74(65)$ \\
\hline \multirow[t]{7}{*}{$\mathrm{Ba}$} & 130 & $0.1056(2)$ & 0.1038 & 0.1059 & 0.1063 & 0.1047 (4) \\
\hline & 132 & 0.1007 (2) & $0.0968(6)$ & 0.1019 (4) & $0.1028(2)$ & 0.1004 (4) \\
\hline & 134 & $2.430(2)$ & $2.438(3)$ & $2.444(4)$ & $2.443(3)$ & $2.448(9)$ \\
\hline & 135 & $6.616(4)$ & $6.640(9)$ & $6.635(12)$ & $6.706(9)$ & $6.627(18)$ \\
\hline & 136 & $7.872(6)$ & $7.949(12)$ & $7.873(27)$ & $7.916(9)$ & $7.892(22)$ \\
\hline & 137 & $11.209(8)$ & $11.289(10)$ & $11.148(21)$ & $11.283(11)$ & $11.258(12)$ \\
\hline & 138 & 71.67 (4) & $71.48(6)$ & 71.69 (9) & $71.44(10)$ & $71.57(7)$ \\
\hline
\end{tabular}

Numbers in parenthese are $2 \sigma$ errors of the last figures indicated. The errors less than half unit of the last are omitted. ${ }^{*} R E E$ data of sample $A$ are from Hidaka and Masuda (1988). 
Table 3. concentrations of elements(ppm)

\begin{tabular}{lllll}
\hline & \multicolumn{1}{c}{$A$} & \multicolumn{1}{c}{$S F-29$} & $S F-42 S L$ & $S F-42 S S$ \\
\hline $\mathrm{Rb}$ & $9.56 \pm 0.07$ & & & \\
$\mathrm{Sr}$ & $(2.11 \pm 0.01) \times 10$ & & & \\
$\mathrm{Zr}$ & $(1.26 \pm 0.01) \times 10^{3}$ & $(9.20 \pm 0.10) \times 10^{2}$ & $(7.36 \pm 0.07) \times 10^{2}$ & $(9.27 \pm 0.11) \times 10$ \\
$\mathrm{Mo}$ & & $(1.22 \pm 0.03) \times 10^{2}$ & & \\
$\mathrm{Ru}$ & $(3.50 \pm 0.04) \times 10^{2}$ & $(5.40 \pm 0.09) \times 10$ & & \\
$\mathrm{Pd}$ & $(5.33 \pm 0.06) \times 10$ & $3.02 \pm 0.09$ & $(6.00 \pm 0.29) \pm 10^{-2}$ & \\
$\mathrm{Ag}$ & & $3.87 \pm 0.04$ & $1.66 \pm 0.02$ & \\
$\mathrm{Te}$ & & $5.66 \pm 0.19$ & $(7.76 \pm 0.21) \times 10^{-1}$ & \\
$\mathrm{Ba}$ & $(6.66 \pm 0.04) \times 10^{2}$ & $(2.24 \pm 0.02) \times 10^{2}$ & $(2.37 \pm 0.02) \times 10^{2}$ & $(2.86 \pm 0.02) \times 10$ \\
$\mathrm{La}$ & $(1.00 \pm 0.01) \times 10^{2}$ & $(2.80 \pm 0.02) \times 10$ & $3.84 \pm 0.03$ & $(2.80 \pm 0.02) \times 10$ \\
$\mathrm{Ce}$ & $(3.41 \pm 0.03) \times 10^{2}$ & $(1.07 \pm 0.01) \times 10^{2}$ & $(1.26 \pm 0.01) \times 10$ & $(4.74 \pm 0.04) \times 10$ \\
$\mathrm{Pr}$ & $(8.68 \pm 0.04) \times 10$ & $(2.03 \pm 0.02) \times 10$ & $1.05 \pm 0.01$ & $3.59 \pm 0.04$ \\
$\mathrm{Nd}$ & $(3.55 \pm 0.03) \times 10^{2}$ & $(9.88 \pm 0.10) \times 10$ & $4.56 \pm 0.02$ & $(1.27 \pm 0.01) \times 10$ \\
$\mathrm{Sm}$ & $(7.36 \pm 0.07) \times 10$ & $(1.89 \pm 0.02) \times 10$ & $(9.71 \pm 0.08) \times 10^{-1}$ & $1.32 \pm 0.01$ \\
$\mathrm{Eu}$ & $(1.16 \pm 0.01) \times 10$ & $4.16 \pm 0.04$ & $(2.58 \pm 0.03) \times 10^{-1}$ & $(1.24 \pm 0.01) \times 10^{-1}$ \\
$\mathrm{Gd}$ & $(1.59 \pm 0.01) \times 10$ & $8.60 \pm 0.08$ & $1.05 \pm 0.01$ & $(8.78 \pm 0.09) \times 10^{-1}$ \\
$\mathrm{Td}$ & $1.74 \pm 0.01$ & $(9.95 \pm 0.08) \times 10^{-1}$ & $(1.39 \pm 0.01) \times 10^{-1}$ & $(9.16 \pm 0.09) \times 10^{-2}$ \\
$\mathrm{Dy}$ & $5.02 \pm 0.04$ & $4.45 \pm 0.05$ & $(8.31 \pm 0.08) \times 10^{-1}$ & $(4.34 \pm 0.04) \times 10^{-1}$ \\
$\mathrm{Ho}$ & $1.96 \pm 0.01$ & $(8.40 \pm 0.08) \times 10^{-1}$ & $(3.07 \pm 0.03) \times 10^{-1}$ & $(6.63 \pm 0.06) \times 10^{-1}$ \\
$\mathrm{Er}$ & $3.77 \pm 0.03$ & $2.16 \pm 0.02$ & $(9.12 \pm 0.09) \times 10^{-1}$ & $(2.18 \times 0.02) \times 10^{-1}$ \\
$\mathrm{Tm}$ & $(4.34 \pm 0.04) \times 10^{-1}$ & $(2.03 \pm 0.02) \times 10^{-1}$ & $(1.30 \pm 0.02) \times 10^{-1}$ & $(2.03 \pm 0.02) \times 10^{-2}$ \\
$\mathrm{Yb}$ & $2.91 \pm 0.03$ & $1.35 \pm 0.01$ & $(7.70 \pm 0.08) \times 10^{-1}$ & $(1.83 \pm 0.02) \times 10^{-1}$ \\
$\mathrm{Lu}$ & $(5.27 \pm 0.05) \times 10^{-1}$ & $(2.22 \pm 0.02) \times 10^{-1}$ & $(1.74 \pm 0.02) \times 10^{-1}$ & $(3.82 \pm 0.05) \times 10^{-2}$ \\
\hline
\end{tabular}

Table 4. Proportions of fissiogenic abundance to the total (fissiogenic pius natural) for each element

(\%)

\begin{tabular}{|c|c|c|c|c|}
\hline & A & SF-29 & SF-42SL & SF-42SS \\
\hline $\mathrm{Rb}$ & 0.3 & & & \\
\hline $\begin{array}{l}\mathrm{Sr} \\
\mathrm{Zr} \\
\mathrm{Mo}\end{array}$ & $\begin{array}{r}0 \\
40\end{array}$ & ${ }_{53}^{2.0}$ & $\begin{array}{l}0 \\
0\end{array}$ & 0 \\
\hline $\mathrm{Ru}$ & 100 & 100 & & \\
\hline $\begin{array}{l}\mathrm{Pd} \\
\mathrm{Ag} \\
\mathrm{Te}\end{array}$ & 100 & $\begin{array}{r}100 \\
29 \\
91\end{array}$ & $\begin{array}{c}100 \\
1.8 \\
12\end{array}$ & 0 \\
\hline $\mathrm{Ba}$ & 0 & 0 & 0 & 0 \\
\hline $\mathrm{La}$ & 32 & 72 & 38 & 9.0 \\
\hline $\mathrm{Ce}$ & 40 & 52 & 11 & 5.0 \\
\hline $\mathrm{Nd}$ & 82 & 70 & 25 & 12 \\
\hline $\begin{array}{l}\mathrm{Sm} \\
\mathrm{Eu}\end{array}$ & 89 & 62 & 18 & 5.4 \\
\hline Gd & 14 & 4.8 & 1.2 & 0.78 \\
\hline
\end{tabular}

tional method by Te, Pd, Nd, Sm and/or Gd isotope ratios (Ruffenach et al., 1976), the proportions of fission for ${ }^{235} \mathrm{U},{ }^{238} \mathrm{U}$ and ${ }^{239} \mathrm{Pu}$ to total fission can be calculated. However, the results obtained here show a wide variation of the proportions in question and it is difficult to evaluate definitely their numerical values. (References about empirical yields for ${ }^{235} \mathrm{U}$ (thermal), ${ }^{238} \mathrm{U}$ (fast) and ${ }^{239} \mathrm{Pu}$ (thermal) are after Crouch (1977).) When considerations are restricted to isotopic compositions of $\mathrm{Pd}$ and $\mathrm{Te}$ in samples A, SF-29 and SF-42SL, it is concluded that the fission products depend greatly on the fission of ${ }^{235} \mathrm{U}$. In the following, we will deal with the fission in our samples in terms of the contribution from pure ${ }^{235} \mathrm{U}$.

We have examined the geochemical behavior of fissiogenic nuclides from the comparison of fission patterns between empirical curves and measured ones. In addition, most of the nuclides corresponding to 140-150 mass range, i.e. light REE, have large neutron capture cross sections and are subject to interaction with neutrons. The isotopic compositions of these elements offer much important information concerning neutron fluence. On the other hand, the nuclides corresponding to another maximal yield peak (90-100 in mass region involving $\mathrm{Zr}$, Mo and $\mathrm{Ru})$ are not sensitive to neutrons, because they own very small neutron capture cross sections. It is considered that the isotopic anomalies of these nuclides are caused largely by fission, and not affected by neutron capture reactions. Moreover, the fission yields of nuclides in the valley between two fission peaks, are sensitive to neutron energy (e.g., Crouch, 1977), and will give a clue to the average neutron energy. Especially these three mass regions, (two max- 

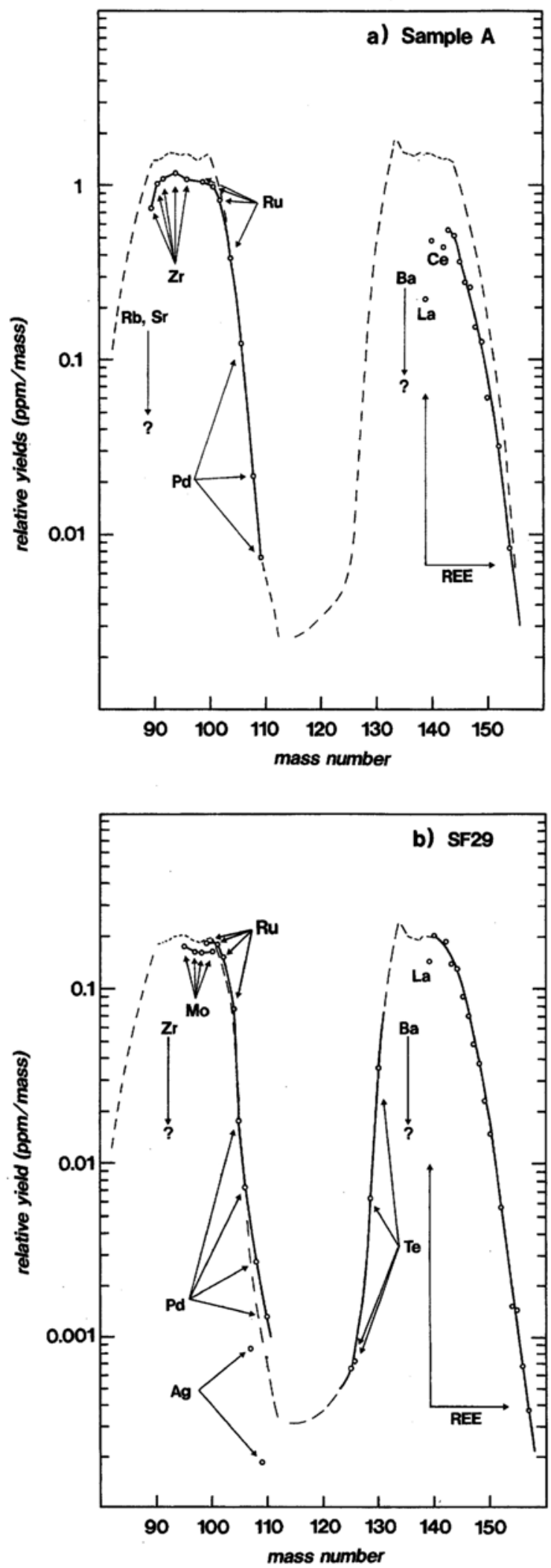

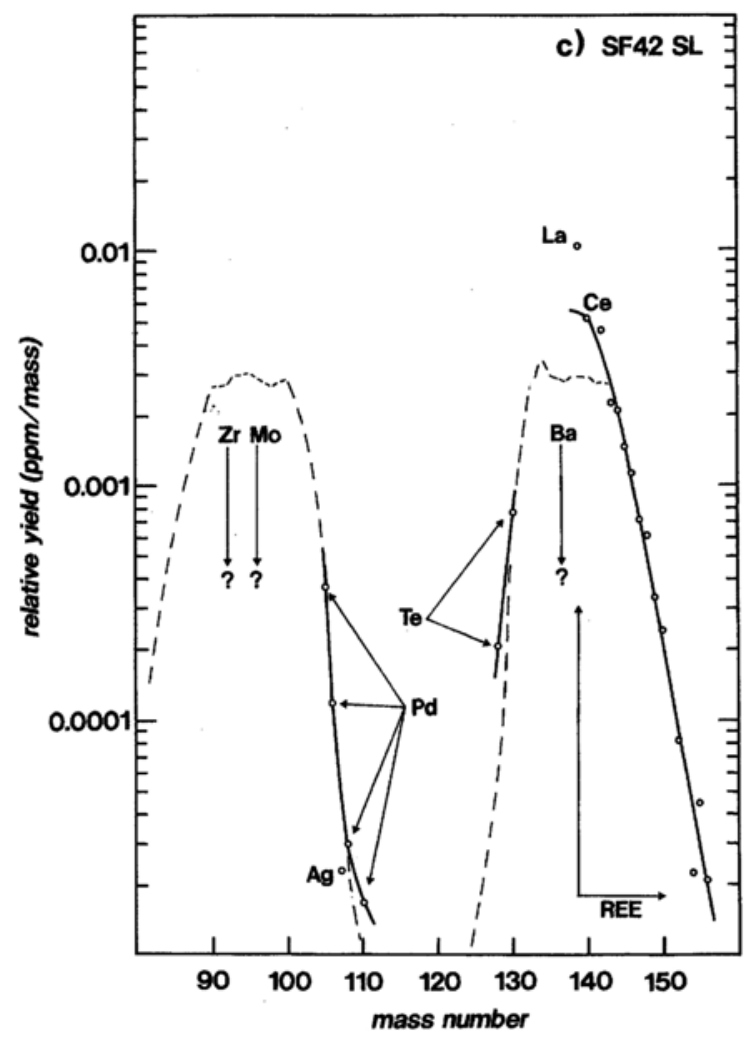

Fig. 2. Measured fission product yield curves of samples (a) $A$, (b) $S F-29$, and (c) $S F-42 S L$. The broken lines in the figures are theoretical curves obtained for pure ${ }^{235} U$ fission (See text).

imal yield regions, i.e., $90-100$ and $130-140$, and minimal yield region, $100-130$, in mass number) are important in the construction of the fission yield curves. Figures 2-a, 2-b and 2-c show fission product yield curves for samples A, SF-29 and SF-42SL, respectively. In these diagrams, open circles connected with solid lines represent measured values. For the sake of reference, the empirical curves (broken lines) are adjusted to the measured curve with respect to the points for $\mathrm{Pd}, \mathrm{Te}$ and $\mathrm{Gd}$ isotopes. The reasons of choice of Pd, Te and Gd for curve fitting are as follows: (i) It has been previously reported that the retention of Te is excellent, and that of Pd is also considerably good (Curtis et al., 1989). (ii) In our previous paper (Hidaka and Masuda, 1988), Gd isotopes were found to be reliable for the estimation of nuclear parameters because of their good retentivity. (iii) Actually, as an independent 
result in our observations in overlapping the obtained plot with the empirical curve, the empirical curve is in fairly good agreement with the measured one at the positions of Pd, Te and Gd.

The clear difference between measured and empirical curves appear at the valley, because the empirical lines in Figs. 2-a, 2-b and 2-c are fission-products yield curves for pure ${ }^{235} \mathrm{U}$. Besides, it must be born in mind that the fission product yield curves are more or less variable depending on the neutron energy for the same parent nuclides. But those two curves are in fair agreement in other regions. Anyway, the current data are admittedly too limited to further quantitative considerations about the pre-fissioned nuclides, particularly with respect to the minimal valley.

We can apply the degree of deviation of "actually measured" from empirical fission yield curves to estimate the retentivities of fissiogenic nuclides.

\section{Behavior of REE}

Isotopic compositions and abundances of REE in some Oklo samples had been already reported (Loubet and Allegre, 1977, Holliger and Devillers, 1981, Hidaka et al., 1988). Because some of REE nuclides are greatly affected by neutron capture reactions and that the retentivities of REE are generally good, isotopic data of REE have served as relative indicators of nuclear parameters (neutron fluence, temperature etc.). Previous estimations of these parameters have been made successfully by use of combination of $\mathrm{Nd}$ and $\mathrm{Sm}$ isotopic data (Holliger and Devillers, 1981; Loubet and Allegre, 1977; Hidaka and Masuda, 1988).

Isotopic anomalies of REE can be theoretically interpreted. As shown in Table 2, isotopic compositions of light REE are very anomalous, whereas those of heavy REE are less anomalous. Production of light REE by fission are much higher than those of heavy REE, and considerable amounts of fission fragments have been accumulated in samples. In addition, some REE nuclides (for example ${ }^{149} \mathrm{Sm},{ }^{155} \mathrm{Gd}$ and ${ }^{157} \mathrm{Gd}$ etc.) have so large neutron capture cross sections that such nuclides are subject to neutron capture, and their isotopic abundances are much less than those of terrestrial standard values. Naturally, the frequency of neutron capture reactions mainly depends on neutron fluence in the reactors. To be sure, the extent of isotopic fractionation of such nuclides derived from neutron capture, as ${ }^{150} \mathrm{Sm},{ }^{156} \mathrm{Gd}$ and ${ }^{158} \mathrm{Gd}$ correlates with the amount of neutron fluence (see Table 1 and isotopic data in Table 2). Thus far, it has been estimated that these isotopic anomalies can be recognized at present owing to the good retention of fissiogenic REE in the reactors. However, scrutiny of details of retentivity of each REE in the reactor has not been carried out yet.

The data regarding $\mathrm{Eh}-\mathrm{pH}$ diagrams (Brookins, 1978) suggest that a series of REE are difficult to move and have been well retained in the reactors. In this paper, we shall discuss the mobilities of lanthanides from the view point of cumulative fission product yields obtained by quantitative measurement of nuclides concerned.

As seen in Fig. 2, it is easy to recognize that $\mathrm{Nd}, \mathrm{Sm}$ and Gd in A, SF-29 and SF-42SL fall on the same curve, but that only $\mathrm{La}$ and/or $\mathrm{Ce}$ is evidently off the curve. Further, deviations of La and $\mathrm{Ce}$ in $\mathrm{A}$, and $\mathrm{La}$ in SF-29 are negative, while those of $\mathrm{La}$ and $\mathrm{Ce}$ in SF-42SL are positive.

Three interpretations are conceivable about positive deviation of $\mathrm{La}$ from the curve for SF42; (i) the effect of neutron capture by ${ }^{138} \mathrm{Ba}$, (ii) local enrichment of fissiogenic $\mathrm{La}$ and $\mathrm{Ce}$, and (iii) the error derived from limitation of the method of estimation. Detailed explanation of each possibility is as follows.

(i) In the reactor, ${ }^{138} \mathrm{Ba}$ captures neutron and turns to ${ }^{139} \mathrm{La}$ by $\beta^{-}$decay in the following way:

$$
{ }^{138} \mathrm{Ba}(\mathrm{n}, \gamma){ }^{139} \mathrm{Ba} \stackrel{\beta^{-}}{\longrightarrow}{ }^{139} \mathrm{La}
$$

The neutron capture cross section of ${ }^{138} \mathrm{Ba}$ is not so large ( 0.4 barn for thermal neutron). But the effect of neutron capture of $\mathrm{Ba}$ cannot be neglected because of the large difference in abundance between ${ }^{138} \mathrm{Ba}$ and ${ }^{139} \mathrm{La}$. The observed abundance of ${ }^{138} \mathrm{Ba}(170 \mathrm{ppm})$ is higher than that 
of fissiogenic ${ }^{139} \mathrm{La}(0.34 \mathrm{ppm})$. Simply judging from the evaluated neutron fluence $\left(1.7 \times 10^{19}\right.$ $\mathrm{n} / \mathrm{cm}^{2}$ ) and each amount of ${ }^{138} \mathrm{Ba}$ and ${ }^{139} \mathrm{La}$, only $0.4 \%$ of ${ }^{139} \mathrm{La}$ is estimated to have been produced by the neutron capture of ${ }^{138} \mathrm{Ba}$. As shown in the isotopic composition of $\mathrm{Ba}$ (Table 2), however, considerable amount of $\mathrm{Ba}$, including fissiogenic $\mathrm{Ba}$, might have been removed from this sample. There is a possibility that much more $\mathrm{Ba}$ existed during criticality, and a certain amount of $\mathrm{La}$ was produced by neutron capture. Unfortunately one cannot quantitatively estimate the amount of $\mathrm{Ba}$ during the reactor operation, because the isotopic composition of sample is nearly the same as that of terrestrial standard.

(ii) Strictly judging from the pattern of measured yield curve, the yield of not only La but also Ce is slightly higher than the expected yield based on the measured curve for $\mathrm{Nd}, \mathrm{Sm}$ and Gd. In other words, there is a possibility of enrichment of fissiogenic $\mathrm{La}$ and $\mathrm{Ce}$ in this sample. Fissiogenic $\mathrm{La}$ and/or Ce may be enriched as a counterpart of leakage from the central zone of the Oklo reactors.

(iii) In the case of SF-42SL, the amounts of fissiogenic REE were substantially lower than those of SF-29. The curve of SF-42SL composed of $\mathrm{Nd}, \mathrm{Sm}$ and $\mathrm{Gd}$ is smooth at the first glance, but it is argued here that the percentages of fissiogenic fractions are generally low for this sample. So, each value in the yield curve of SF42SL has some errors and the numerical values calculated for $\mathrm{La}$ and $\mathrm{Ce}$ can be subject to relative overestimation, and fall off above the curve.

On the other hand, the fission yield curves of samples A and SF-29 have negative anomalies of $\mathrm{La}$ and/or Ce. Contents of fissiogenic $\mathrm{La}$ and $\mathrm{Ce}$ in two samples are relatively high, and the effect of nuclear production on ${ }^{139} \mathrm{La}$ derived from ${ }^{138} \mathrm{Ba}$ discussed above must be negligibly low. These deviations indicate the partial leakage of fissiogenic ${ }^{139} \mathrm{La},{ }^{140} \mathrm{Ce}$ and ${ }^{142} \mathrm{Ce}$ out of the reactors. Complex causes are likely to be responsible for the partial leakage processes of these fissiogenic nuclides; selective dissolution, adsorption and coprecipitation affected by inclusions such as organic matter (Nagy et al., 1991) and by $\mathrm{pH}$ and redox conditions (Brookins, 1984) in or around reactor. But in the case of REE, their chemical behaviors are coherent with each other. Here our attention should be paid to the chain reactions producing $\mathrm{La}$ and $\mathrm{Ce}$. Primary product decays by successive beta decay processes to its stable isobar. In the case of fissiogenic ${ }^{139} \mathrm{La}$, ${ }^{140} \mathrm{Ce}$ and ${ }^{142} \mathrm{Ce}$, they temporarily become radioactive precursors other than REE in their fission chains, such as $\mathrm{Xe}, \mathrm{Cs}$ and $\mathrm{Ba}$. That is, it is likely that the precursors of fissiogenic $\mathrm{La}$ and/or $\mathrm{Ce}$ nuclides have behaved differently from those of other REE nuclides. Strictly speaking, fissiogenic ${ }^{143} \mathrm{Nd},{ }^{144} \mathrm{Nd},{ }^{145} \mathrm{Nd}$ and ${ }^{146} \mathrm{Nd}$ also temporarily become precursory nuclides other than REE in their fission chains. However, the total half-lives of precursors at elemental stages of $\mathrm{Xe}, \mathrm{Cs}$ and $\mathrm{Ba}$ leading to those Nd nuclides are much shorter than those of the corresponding precursors for ${ }^{139} \mathrm{La},{ }^{140} \mathrm{Ce}$ and ${ }^{142} \mathrm{Ce}$ (Lederer and Shirley, 1978). In addition, other fissiogenic REE nuclides experience only REE precursors in the fission chains. This study shows again that negative deviation of fissiogenic $\mathrm{La}$ and/or $\mathrm{Ce}$ appears in some Oklo samples with abundant fission products. It should be noted here that the deviation of $\mathrm{La}$ is markedly larger than that of

Table 5. Deviations of isotopic composition of barium from standard values

(deviations in permil)

\begin{tabular}{lcccccc}
\hline & $130 / 134$ & $132 / 134$ & $135 / 134$ & $136 / 134$ & $137 / 134$ & $138 / 134$ \\
\hline A & $-20 \pm 4$ & $-42 \pm 6$ & $+0.3 \pm 2.1$ & $+6.5 \pm 2.3$ & $+3.8 \pm 1.9$ & $-5.9 \pm 1.8$ \\
SF-29 & $-2.9 \pm 3.9$ & $+6.1 \pm 4.8$ & $-2.9 \pm 2.6$ & $-5.6 \pm 3.9$ & $-11 \pm 3$ & $-5.4 \pm 2.3$ \\
SF-42SL & $+1.3 \pm 3.1$ & $+15 \pm 3$ & $+8.2 \pm 2.1$ & $+0.2 \pm 2.0$ & $+1.2 \pm 1.9$ & $-8.5 \pm 2.1$ \\
SF-42SS & $-16 \pm 6$ & $-10 \pm 6$ & $-5.8 \pm 4.6$ & $-4.8 \pm 4.7$ & $-3.1 \pm 4.0$ & $-8.7 \pm 3.9$ \\
\hline
\end{tabular}

Errors are $2 \sigma$ mean. 
$\mathrm{Ce}$, in conformity with the reasoning coming from the considerations of precursors.

In parallel with the interpretation of negative anomaly of La and/Ce in A and SF-29, it is highly probable that the positive anomalies for $\mathrm{La}$ and $\mathrm{Ce}$ in SF-42SL are due to local enrichment of fissiogenic $\mathrm{La}$ and $\mathrm{Ce}$.

\section{Rubidium Strontium and Barium}

$\mathrm{Rb}, \mathrm{Sr}$ and $\mathrm{Ba}$ had been theoretically produced in great quantities in the reactor. However, their retention is not so good and most of them have disappeared. The isotopic compositions of these three elements in the samples are almost the same as those in terrestrial standards, indicating the complete loss of fissiogenic $\mathrm{Rb}, \mathrm{Sr}$ and $\mathrm{Ba}$.

One of our purposes of $\mathrm{Ba}$ isotope measurement was to trace ${ }^{135} \mathrm{Cs}\left(\mathrm{T}_{1 / 2}=2.95 \times 10^{6} \mathrm{y}\right)$ and ${ }^{137} \mathrm{Cs}\left(\mathrm{T}_{1 / 2}=30 \mathrm{y}\right)$ from the isotopic deviation of ${ }^{135} \mathrm{Ba}$ and ${ }^{137} \mathrm{Ba}$. Table 5 shows the deviations of the isotopic composition for $\mathrm{Ba}$ from the Ba standard. Isotope ratios are normalized against ${ }^{134} \mathrm{Ba}$, because ${ }^{134} \mathrm{Ba}$ is non-fissiogenic. SF-42SL shows a relatively large deviation $+8.2 \pm 2.1 \%$ for ${ }^{135} \mathrm{Ba}$, and a slight deviation $+1.2 \pm 1.9 \%$ for ${ }^{137} \mathrm{Ba}$. Sample A also has positive deviations for ${ }^{135} \mathrm{Ba}$ and ${ }^{137} \mathrm{Ba}$. These observations would suggest the addition of fissiogenic Cs to the samples, but there are also other possibilities to cause a slight isotopic deviation, such as the neutron capture reaction of $\mathrm{Ba}$ and $\mathrm{Cs}$, and a trace amount of fissiogenic Ba remaining in the samples. In particular, the deviations of ${ }^{130} \mathrm{Ba}$ and ${ }^{132} \mathrm{Ba}$ with primarily low isotopic abundance may be enhanced by these factors. On the other hand, SF-29 and SF-42SS have negative deviations for ${ }^{135} \mathrm{Ba}$ and ${ }^{137} \mathrm{Ba}$. ${ }^{134} \mathrm{Ba}$ is non-fissiogenic, but is produced by neutron capture of ${ }^{133} \mathrm{Cs}$. Therefore, in these two cases the effect of addition of ${ }^{134} \mathrm{Cs}$ produced by neutron capture of ${ }^{133} \mathrm{Cs}$ might be higher than those of ${ }^{135} \mathrm{Cs}$ and ${ }^{137} \mathrm{Cs}$. Overall, one cannot readily evaluate the behavior of fissiogenic $\mathrm{Cs}$ from our isotopic study of $\mathrm{Ba}$, and further precise and systematic investigations are required.

\section{Palladium, Silver and Tellurium}

As it is evident from the fact that the best fit between the empirical and the observed yield curves was achieved at the points for $\mathrm{Pd}$ and $\mathrm{Te}$, their fissiogenic nuclides have been retained considerably in SF-29 and SF-42SL samples. The relative retentivity of $\mathrm{Pd}$ to $\mathrm{Te}$ is quantitatively evaluated to be $0.85-0.90$ for these two samples, compared with the empirical values for fission of ${ }^{235} \mathrm{U}$. (That of Gd is also high, 0.94-1.1.)

Primordial $\mathrm{Pd}$ and $\mathrm{Te}$ must be rare in samples, and most of them reflect typically fissiogenic isotopic composition. The presence of ${ }^{104} \mathrm{Pd}$ in samples $\mathrm{A}$ and SF-42SL reveals its production by the neutron capture of ${ }^{103} \mathrm{Rh}$. Especially, for fissiogenic $\mathrm{Pd}$ and $\mathrm{Te}$, the fission yields of their constituent isotopes change substantially with change in mass number. These fission yields vary depending on parent nuclides ${ }^{235} \mathrm{U},{ }^{238} \mathrm{U}$ and $\left.{ }^{239} \mathrm{Pu}\right)$ as described above. Relative cumulative fission yields of $\mathrm{Pd}$ and $\mathrm{Te}$ for thermal and/or epicadmium neutrons have been precisely measured (Shima et al., 1978, and De Laeter et al., 1982). These empirical yields for $\mathrm{Pd}$ and Te are to a considerable extent subject to the energy of induced neutrons. In our study, the evaluation of fission contribution for ${ }^{235} \mathrm{U},{ }^{238} \mathrm{U}$ and ${ }^{239} \mathrm{Pu}$ from isotopic data of $\mathrm{Pd}$ and Te was of limited success. But it may be possible to determine this contribution, if more dependable and precise data are available about the dependency of fission yields on neutron energy.

It is difficult to estimate the proportions of primarily fissiogenic $\mathrm{Ag}$ isotopes to total $\mathrm{Ag}$,

Table 6. Isotopic abundance and fission product yield of zirconium

\begin{tabular}{cccccccc}
\hline \multicolumn{3}{c}{ Mass number } & \multicolumn{2}{c}{ composition (atom \%) } & & \multicolumn{3}{c}{ yield } \\
\cline { 6 - 7 } \cline { 5 - 7 } \cline { 5 - 7 } & calcd. & obsd. & & calcd. & obsd. & $\begin{array}{c}\text { obsd./ } \\
\text { calcd. }\end{array}$ \\
\hline 90 & 19.20 & 14.32 & & 1.48 & 0.799 & 0.540 \\
91 & 19.40 & 19.82 & & 1.50 & 1.09 & 0.727 \\
92 & 19.67 & 20.91 & & 1.52 & 1.14 & 0.750 \\
94 & 21.14 & 23.05 & & 1.63 & 1.23 & 0.755 \\
96 & 20.58 & 21.89 & & 1.59 & 1.15 & 0.723 \\
\hline
\end{tabular}

calcd. $=$ calculated value

obsd. $=$ observed value of sample $A$ 
owing to the effects of neutron capture reactions. $\mathrm{Ag}$ has only two isotopes, and both of two nuclides have enough neutron capture cross sections to react. However it is difficult to consider that significant amount of fissiogenic $\mathrm{Ag}$ has disappeared because of only neutron capture reactions. Among REE, some fissiogenic nuclides with larger cross sections than those of $\mathrm{Ag}$ isotopes have remained unaffected. In Figs. 2-b and 2-c, the currently observed values for Ag nuclides are plotted without any corrections taking into account the effect of neutron capture reactions. Judging from the total amount of $\mathrm{Ag}$, it can be roughly estimated that more than half of fissiogenic Ag has disappeared.

\section{Zirconium}

It is empirically known that $\mathrm{Zr}$ nuclides are produced in large quantities by fission. In particular, one could expect some irregularity of ${ }^{90} \mathrm{Zr}$ among $\mathrm{Zr}$ nuclides, because ${ }^{90} \mathrm{Zr}$ becomes radioactive precursor ${ }^{90} \mathrm{Sr}$ with a half-life of 28.8 y. Other $\mathrm{Zr}$ nuclides than ${ }^{90} \mathrm{Zr}$ do not experience such a long life precursor as ${ }^{90} \mathrm{Sr}$. But the isotope compositions of $\mathrm{Zr}$ in samples SF-29, SF-42SL and SF-42SS are almost the same as that of the terrestrial standard. We speculate that the intense redistribution between the fissiogenic and natural $\mathrm{Zr}$ brought about the results observed here. Because of such considerable terrestrial contamination, the estimation of fissiogenic fraction turns out to be difficult. In view of the nearly normal isotopic composition and rather high abundance of $\mathrm{Zr}$ in these samples, primarily fissiogenic $\mathrm{Zr}$ is considered to have been removed.

However, as shown in Fig. 2-a, fissiogenic $\mathrm{Zr}$ have been preserved in uraninite with high uranium content, such as sample $\mathrm{A}$. $\mathrm{Zr}$ fission product yields of sample $A$ are presented in Table 6. The "calculated values" in this Table are from Crouch (1977). The fissiogenic nuclides of $\mathrm{Zr}$, except for ${ }^{90} \mathrm{Zr}$, turn out to have been retained at $71-75 \%$. However, only ${ }^{90} \mathrm{Zr}$ was significantly lowered relative to other $\mathrm{Zr}$ nuclides. According to our calculation, 17-20\% of the fissiogenic ${ }^{90} \mathrm{Zr}$ is more depleted than the
Table 7. Fission product yield (ppm/mass) of ruthenium

\begin{tabular}{|c|c|c|c|c|c|c|}
\hline \multirow{2}{*}{ mass number } & \multicolumn{3}{|c|}{ sample A } & \multicolumn{3}{|c|}{ SF-29 } \\
\hline & calcd. & obsd. & $\begin{array}{l}\text { obsd./ } \\
\text { calcd. }\end{array}$ & calcd. & obsd. & $\begin{array}{l}\text { obsd./ } \\
\text { calcd. }\end{array}$ \\
\hline 99 & 1.55 & 1.05 & 0.677 & 0.204 & 0.168 & 0.82 \\
\hline $\begin{array}{l}101 \\
102 \\
104\end{array}$ & $\begin{array}{l}1.29 \\
1.00 \\
0.463\end{array}$ & $\begin{array}{l}1.15 \\
0.855 \\
0.424\end{array}$ & $\begin{array}{l}0.891 \\
0.855 \\
0.916\end{array}$ & $\begin{array}{l}0.170 \\
0.139 \\
0.0608\end{array}$ & $\begin{array}{l}0.165 \\
0.141 \\
0.0609\end{array}$ & $\begin{array}{l}0.97 \\
1.01 \\
1.00\end{array}$ \\
\hline
\end{tabular}

calcd. $=$ calculated value

obsd. $=$ observed value

other four fissiogenic nuclides. This implies that ${ }^{90} \mathrm{Sr}$ might have been lost to some extent during criticality of the Oklo reactors.

\section{Molybdenum}

Fission product yields of ${ }^{95} \mathrm{Mo},{ }^{97} \mathrm{Mo},{ }^{98} \mathrm{Mo}$ and ${ }^{100} \mathrm{Mo}$ are high. Isotopic anomalies in SF-29 are reasonable and endorse the considerably good preservation of the fissiogenic Mo nuclides. On the other hand, isotopic composition of SF42SL is nearly the same as that of terrestrial standard value, suggesting that the retentivity of fissiogenic Mo is variable depending on the environmental conditions.

\section{Ruthenium}

The contents of $\mathrm{Ru}$ in the Oklo samples are high in contrast to those in common crustal rocks because of accumulation of high yield fission fragments. Further, isotopic compositions of Ru in samples A and SF-29 are found to be fissiogenic; non-fissiogenic nuclides ${ }^{96} \mathrm{Ru},{ }^{98} \mathrm{Ru}$ and ${ }^{100} \mathrm{Ru}$ could not be detected. As can be seen from Figs. 2-a and 2-b, fissiogenic Ru have been well retained in the reactor.

There is a possibility that behavior of Tc could be estimated from isotopic fractionation of ${ }^{99} \mathrm{Ru}$ (Curtis, 1986). ${ }^{99} \mathrm{Ru}$ has behaved differently from other fissiogenic Ru nuclides, because ${ }^{99} \mathrm{Ru}$ temporarily becomes ${ }^{99} \mathrm{Tc}$ with a long halflife $\left(\mathrm{T}_{1 / 2}=2.1 \times 10^{5} \mathrm{y}\right)$ in its fission chain. Table 7 shows the comparison of fission product yields between calculated and measured values in samples $\mathrm{A}$ and SF-29. Fissiogenic $\mathrm{Ru}$ has been well preserved in both two samples, A and SF- 
29 , but the relative abundance values of ${ }^{99} \mathrm{Ru}$ are lower than those of other three Ru nuclides. The depletion of ${ }^{99} \mathrm{Ru}$ suggests the partial leakage of ${ }^{99} \mathrm{Tc}$ out of the Oklo reactors.

\section{Conclusions}

Construction of cumulative fission product yield curves over a wide range based on nuclide abundances leads us to the following information on retention of fissiogenic nuclides. One can conclude that $\mathrm{Ru}, \mathrm{Pd}, \mathrm{Te}$ and most of REE (Nd, $\mathrm{Sm}, \mathrm{Gd}$ ) have been well retained on the macroscopic scale. These nuclides seem fairly stable even under the geological conditions where $\mathrm{Rb}, \mathrm{Sr}, \mathrm{Zr}$, Mo and/or $\mathrm{Ba}$ have been redistributed. In particular, the retention degrees of fissiogenic $\mathrm{Zr}$ and Mo greatly depend upon the chemical and geochemical conditions around the reactor. The nuclides whose precursors behave differently from such end products as ${ }^{90} \mathrm{Zr},{ }^{99} \mathrm{Ru},{ }^{139} \mathrm{La},{ }^{140} \mathrm{Ce}$ and ${ }^{142} \mathrm{Ce}$ may reflect the behaviors of their precursors to a considerable extent. The degree of deviation connected with the different behaviors of precursory nuclides is mainly affected by life-time of their precursors.

Reactor 10 was located underground and was not studied as well yet as reactors 1-9. For this reason, it can be expected that new results may be obtained from the analysis of reactor 10 samples. Our data obtained from fission product yield curves are in general agreement with previous work, but this is the only work carried out on many elements of underground zone samples. The detailed mining works at Oklo reactor zones including ones in the open pit and underground are being carried out. If we can find out a region with a significant enrichment of fissiogenic $\mathrm{Ba}$ in Oklo ores, light will be shed on the more detailed behavior of ${ }^{137} \mathrm{Cs}$ in geological media over a long time span.

Acknowledgments-We thank Dr. I. Fujii, Japan Fuel Technology Corporation, for the donation of samples. We acknowledge Dr. H. Bunno, Geological Survey of Japan, for helpful comments concerning samples. We also like to acknowledge Messrs. T. Ushida, N. Kano, Drs. H. Shimizu and T. Akagi for their assistance in the isotopic measurements. We are also very much grateful for the critical reading of the manuscript and valuable comments by Drs. B. Nagy, J.R. De Laeter, R. Naudet and P. K. Kuroda. Dr. Ph. Holliger kindly sent useful references of Oklo study.

\section{REFERENCES}

Brookins, D. G. (1978) Eh-pH diagrams for elements from $Z=40$ to $Z=52$ : Application to the Oklo natural reactor, Gabon. Chem. Geol. 23, 325-342.

Brookins, D. G. (1984) Geochemical Aspects of Radioactive Waste Disposal. Springer Verlag, New York.

Bunno, H., Sakamaki, Y. and Koide, H. (1985) The report of geochemical researches on Oklo ore. Geological Survey of Japan.

Chen, J. H. and Wasserburg, G. J. (1981) Isotopic determination of uranium in picomole and subpicomole quantities. Anal. Chem. 53, 2060-2067.

Crouch, E. A. C. (1977) Fission-product yields from neutron-induced fission. Atomic data and nuclear data tables 19, 417-532.

Curtis, D. B. (1986) Geochemical controls on ${ }^{99} \mathrm{Tc}$ transport and retention. Chem. Geol. 55, 227-231.

Curtis, D. B., Benjamin, T. M., Gancarz, A. J., Loss, R. D., Rosman, K. J. R., De Laeter, J. R., Delmore, J. E. and Maeck, W. J. (1989) Fission product retention in the Oklo natural fission reactors. Appl. Geochem. 4, 49-62.

De Laeter, J. R., Rosman, K. J. R. and Smith, C. L. (1980) The Oklo natural reactor: Cumulative fission yields and retentivity of the symmetric mass region fission products. Earth Planet. Sci. Lett. 50, 238246.

De Laeter, J. R., Rosman, K. J. R. and Boldeman, J. W. (1982) Relative yields of stable tellurium isotopes in neutron-induced fission. Aust. J. Physics 35, 385-391.

Eugster, O, Tera, F. and Wasserburg, G. J. (1969) Isotopic analyses of barium in meteorites and in terrestrial samples. J. Geophys. Res. 74, 3897-3908.

Faure, G. and Powell, J. L. (1972) Strontium Isotope Geology, Springer Verlag, New York.

Gauthier-Lafaye, F. and Weber, F. (1989) The Francevillian (lower Proterozoic) uranium ore deposits of Gabon. Econ. Geol. 84, 2267-2285.

Hagemann, R. and Roth, E. (1978) Relevance of the studies of the Oklo natural nuclear reactors to the storage of radioactive wastes. Radiochim. Acta 25, 241-247.

Hidaka, H., Masuda, A., Fujii, I. and Shimizu, H. (1988) Abundance of fissiogenic and pre-reactor natural rare-earth elements in a uranium ore sample from Oklo. Geochem. J. 22, 47-54. 
Hidaka, H. and Masuda, A. (1988) Nuclide analyses of rare earth elements of the Oklo uranium ore samples: a new method to estimate the neutron fluence. Earth Planet. Sci. Lett. 88, 330-336.

Hirata, T., Shimizu, H., Akagi, T., Sawatari, H. and Masuda, A. (1988) Precise determination of rare earth elements in geological standard rocks by inductively coupled plasma source mass spectrometry. Anal. Sci. 4, 637-643.

Holliger, P. and Devillers, C. (1981) Contribution à l'étude de la température dans les réacteurs fossiles d'Oklo par la mesure du rapport isotopique du lutétium. Earth Planet. Sci. Lett. 52, 76-84.

Holliger, P. (1991) Systêmatique U-Pb et étude isotopique in situ ${ }^{235} \mathrm{U}$-produits de fission de la zone de réaction hybride du sondage SF. 29 (Zone 10): autres zones d'intérêt sur le site d'Oklo pour les études futures. Technical report, CEA-DTACENG. No. 18/91.

Kawashima, A. (1990) (personal communication)

Lederer, C. M. and Shirley, V. S. (1978) Table of Isotopes, 7th edition. John Wiley \& Sons, Inc., New York.

Loss, R. D., Rosman, K. J. R. and De Laeter, J. R. (1983) Measurement of $\mathrm{Ag}, \mathrm{Te}$ and $\mathrm{Pd}$ in geochemical reference materials by mass spectrometric isotope-dilution analysis. Talanta 30, 831-835.

Loss, R. D., Rosman, K. J. R. and De Laeter, J. R. (1984) Transport of symmetric mass region fission products at the Oklo natural reactors. Earth Planet. Sci. Lett. 68, 240-248.

Loubet, M. and Allegre, C. J. (1977) Behavior of the rare earth elements in the Oklo natural reactor. Geochim. Cosmochim. Acta 41, 1539-1548.

Nagy, B., Gauthier-Lafaye, F., Holliger, P., Davis,
D. W., Mossman, D. J., Leventhal, J. S., Rigali, M. J. and Parnell, J. (1991) Organic matter and containment of uranium and fissiogenic isotopes at the Oklo natural reactors. Nature 354, 472-475.

Natural Fission Reactors (1978) Proceedings of $a$ Meeting of the Technical Committee on Natural Fission Reactors, IAEA, Vienna.

Roth, E. (1977) The discovery and study of the nuclear reactor in Oklo. J. Radioanal. Chem. 37, 65-78.

Ruffenach, J. C., Menes, J., Devillers, C., Lucas, M. and Hagemann, R. (1976) Etudes chimiques et isotopiques de l'uranium, du plomb et de plusieurs produits de fission dans un échantillon de minerai du réacteur naturel d'Oklo. Earth Planet. Sci. Lett. 30, 94-108.

Shima, M. (1978) The isotopic composition and the atomic weight of zirconium. Int. J. Mass Spectrom. Ion Phys. 28, 129-140.

Shima, M., Thode, H. G. and Tomlinson, R. H. (1978) Cumulative yields of stable and long-lived isotopes of ruthenium and palladium in neutron-induced fission. Can. J. Phys. 56, 1340-1352.

Terada, K., Matsumoto, K. and Kiba, T. (1975) Neutron-activation analysis of selenium, osmium and ruthenium in rocks, sediments and biological materials by successive distillations with three kinds of strong phosphoric acid reagents. Bull. Chem Soc. Jpn. 48, 2567-2571.

The Oklo Phenomenon (1975) Proceedings of a Symposium on the Oklo Phenomenon, IAEA, Vienna.

Tromp, R. L., Delmore, J. E., Nielsen, R. A. and Chapman, T. C. (1981) Mass spectrometric systems and techniques for fission product analysis. ENICO-1094. 